\title{
Castles in the air
}

Colin Norman reports from Washington on a heavily-criticised study from the Environmental Protection Agency (EPA)

A MASSIVE study of the health effects of exposure to low levels of air pollutants, conducted by the EPA at a cost of some $\$ 22$ million, is so riddled with errors and shortcomings that the results produced so far are virtually useless. That verdict, reached by a team of investigators working for two Congressional subcommittees, is likely to prove more than a mere embarrassment to EPA, for the study was originally expected to provide the basis for the agency's air pollution regulations.

The study, known as the Community Health and Environmental Surveillance System (CHESS), was an ambitious effort to collect and compare data on the levels of pollutants and the incidence of a variety of health problems in six US cities. Data collection began in the late 1960s and ended last year, and the first results (covering information collected in 1970 and 1971) were published in the form of a monograph in May 1974. The monograph purported to show that there is an association between various health problems, such as the incidence of asthma and heart and lung disorders, and levels of sulphur dioxide in the atmosphere.

Though such a correlation is not exactly surprising-the London smogs of the 1940s and $1950 \mathrm{~s}$ had provided a rather graphic demonstration of the association between high levels of pollutants and severe health problemsthe CHESS findings and the methodology used in the study have encountered considerable scientific criticism.

Most of the criticism has been concerned with the methods used in gathering and interpreting the data, but last February the study was dealt a severe new blow when the Los Angeles Times published an article alleging that the finding in the first CHESS monograph had been deliberately distorted by an EPA official "in an effort to prove that pollution from sulphurbearing fuels has an adverse impact on human health". The article implied that the findings had been distorted in order to provide scientific justification for EPA's air pollution regulations.

The allegations set off a stampede of lobbyists from electricity companies, coal producers and other industries to Capitol Hill, to urge that no new regulations be adopted at least until the CHESS study has been examined. The matter was urgent because Congress was then about to consider amendments to the Clean Air Act, and consequently two subcommittees conducted a public hearing to examine the charges. The hearing produced a score of witnesses, most of whom flatly denied that any deliberate distortion of the data had taken place. But the hearing did not go deeply into the methodology behind the CHESS study or the validity of the data. For that purpose, a Congressional staff investigation was launched, under the guidance of Congressman George E. Brown Jr, and with the help of a battery of scientific consultants. It was the result of that investigation which was published last week.

The investigating team reported that the CHESS study provides "a picture of a program pressured by EPA management-imposed time constraints to meet legislated mandates for promulgating new standards, hampered by inadequate mechanisms to detect and correct technical problems, and handicapped by budgetary and management restrictions placed on the program after it was well under way". The upshot, Brown said last week, is that the CHESS results published so far "have virtually no quantitative value".

Many of the problems stem from the fact that atmospheric measuring techniques, used particularly in the early stages, are too imprecise to yield good information. For example, an attempt to see whether there is a threshold level of sulphur dioxide pollution below which health effects are not experienced was hampered by the fact that the measuring technique could not detect concentrations of the pollutant below $25 \mu \mathrm{g} \mathrm{m}^{-3}$, and the uncertainty in the measurements sometimes exceeded $100 \%$.

Most of the CHESS data is still to be analysed, but the Congressional report argues that "there is serious doubt that the analysis even when completed will ever be sufficiently credible to support the stated objectives of the program". EPA has, however, initiated a new monitoring program, known as CHAMP (Community Health Air Monitoring Program), which the Congressional report calls "clearly an improvement in aeronomic pollution measurement", but it won't yield health data because at present it is not coupled with a health monitoring programme.

In other words, regulation of air pollution will continue to be based on imprecise information about the effects of low levels of pollutants on human health, a fact which is sure to be exploited to the full by purveyors of sulphur pollutants. They won't have to wait long for an opportunity to state their case, because when Congress returns in January one of its first items of business will be a reconsideration of the Clean Air Act (no agreement was reached last session on proposed amendments to the act. and the matter will be brought up again next session).

It should be noted, however, that although the CHESS study has provided no scientific basis for the present air quality standards, it has provided no reason to reject them.

\section{Warning on fluorocarbons}

Over the shrill objections of the cosmetics industry, the Food and Drug Administration (FDA) and the Consumer Product Safety Commission (CPSC) last week proposed separate actions to reduce and eventually eliminate the use of fluorocarbons in aerosol spray cans. The FDA's proposal, which would involve placing a warning label on fluorocarbon-containing products, was expected; the CPSC action came as a surprise.

FDA has authority over products such as hair sprays, deodorants, perfumes and anti-perspirants, which account for some $80 \%$ of the total release of fluorocarbons into the atmosphere. The action announced last week will require the following statement to be printed on the label of aerosol spray cans containing fluorocarbon propellants:

Warning. Contains a chlorofluorocarbon that may harm the public health and environment by reducing ozone in the upper atmosphere.

No date has yet been set for the regulation to take effect, but barring legal action by the industry to block the proposal, the warning labels will probably be required early next year. The action, noted FDA Commissioner Alexander Schmidt, is only an interim measure-FDA will soon propose a timetable for phasing out all non-essential uses of fluorocarbons entirely.

The CPSC action came in the form of a $5-0$ vote by the commissioners to ban use of fluorocarbons in aerosol products not regulated by FDA. No timetable was set by CPSC for carrying out the ban, however. 